\title{
Типологические и идентификационные признаки поколений
}

\section{Влада И. Пищик}

Донской государственный технический университет, г. Ростов-на-Дону, Российская Федерация

E-mail: vladaph@yandex.ru

\begin{abstract}
Аннотация
Введение. В статье представлен новый взгляА на выявление идентифрикационных и типологических признаков поколений с позиции кАассического (приморАиамистского) и некАассического (конструкционистского) поАходов. Актуальность исследования обусловлена слабой проработкой проблемы выявления иАентификационных признаков поколений в социальной психологии. Перечисляются к^ассификации поАХоАОв к определению понятия «поколение». Рассматриваются уже имеющиеся в науке критерии диффреренциации поколений. Поднимается вопрос субъективных и объективных критериев.

Приводятся исследования в рамках к^ассического подхода, когАа поколение понимается как большая группа, и ее илентификационными признаками выступают неизменные образования (возраст, исторические события жизни, место в роду). Представлены различные типологии поколений России, Америки, Китая, в которых разнятся критерии границ поколений. Показано, что илентисрикация с поколением не всегАа соответствует возрасту респонАента. В конструкционистском поАХОАе реальность жизни поколений преАставлена как текучая и изменяемая, а поколение понимается как мягкая система, идентифрикационные признаки которой трудны Аля фриксации. Аискурс является индикатором текучей илентификации поколений. Приведено сравнение уже имеющихся типологий поколений.
\end{abstract}

Методы. В разделе описана выборка исследования - 300 человек (представители «переходного», «инфрормационного» поколений). Представлены: метолика, измеряющая типы ментальности (В.И. Пищик), метоА свободного описания на тему «Мой поАростковый возраст».

Результаты. Аанный разАел включает результаты исслеАования. У «инорормационного» поколения выражена инновационная ментальность, у «переходного» поколения инновационная, традиционная ментальности. Статистически значимо поАтвержАаются различия межАу социетальностью и инАивиАуалистичностью соАержания текстов. Подчеркивается, что в текстах «переходного» поколения преимущественно излагаются проблема и культурный контекст, а в текстах «инфрормационного» поколения перечисляются фрактология жизни и приобретаемые вещи, предметы. 
ОбсужАение результатов. КАассический и неклассический поАходы К проблеме поколений рассматриваются как Аве альтернативы представленности знания. Аелается вывоА о перспективности применения конструкционистского поАХоАа к психологии поколений.

\section{КАючевые слова}

поколение, к^ассический поАХоА, неклассический поАХоА, признаки иАентифрикации с поколением, типологические признаки поколения, тип ментальности, инновационная ментальность, традиционная ментальность, инфрормационное поколение, переходное поколение

\section{Основные положения}

- с к^ассических позиций поколение в психологии понимается как малоструктурированная социальная группа;

- с нек^ассических позиций поколение выступает как фрорма культурных, кол^ективных репрезентаций;

- илентификационные признаки поколений в классическом рассмотрении жестко ффиксированы и передаются из поколения в поколение;

- иАентификационные признаки поколения в конструкционистском КАюче поАвижны, неустойчивы; они не передаются по прямой трансмиссии;

- типология поколений имеет культурное, социальное и историческое своеобразие.

\section{Благодарности}

Статья подготовлена при финансовой поддержке РФФИ, проект № 18-013-00910 «Динамика ценностей поколений как маркер трансформации социальных отношений в российском обществе».

\section{Для цитирования}

Пищик В.И. Типологические и идентификационные признаки поколений // Российский психологический журнал. 2018. T. 15, № 2. С. 215-236. DOI: 10.21702/rpj.2018.2.9

Материалы статьи получены 26.09.2017 


\title{
Typological and Identifying Characteristics of Generations
}

\author{
Vlada I. Pishchik \\ Don State Technical University, Rostov-on-Don, Russian Federation \\ E-mail: vladaph@yandex.ru
}

\begin{abstract}
Introduction. Little attention has been paid to the study of identifying characteristics of generations in social psychology. This paper: (a) presents a novel view of typological and identifying characteristics of generations within classical (primordial) and nonclassical (constructionist) approaches; (b) classifies approaches to defining the 'generation' concept; (c) considers the existing criteria for differentiating generations; and (d) discusses the issue of subjective and objective criteria. Within the framework of the classical approach the generation is understood as a large group which identifying characteristics include such constant constructs as: age, historical events of life, and a place in the family. The study presents typologies of generations in Russia, America, and China that differ in their criteria for generational boundaries. It is found that respondents' identification with their generation does not always correspond to their age. The constructionist approach suggests that the reality of life of generations is changeable and fluid and defines the generation as a non-rigid system which identifying characteristics are hard to fixate. Discourse is an indicator of the fluid identification of generations. The paper concludes with the comparative analysis of the existing typologies of generations.
\end{abstract}

Methods. The study used the technique for measuring mentality types by V.I. Pishchik and 'My Adolescence' free description technique. The study sample was comprised of 300 individual participants (representatives of the 'transitional' and 'informational' generations).

Results. In brief the research findings indicate that the informational generation is characterized by innovative mentality, while the transitional generation is characterized by both innovative and traditional mentality. The difference between indices of societality and individualism in the analyzed text content is statistically significant. The texts produced by the representatives of the transitional generation mainly contain the problem and the cultural context. The representatives of the informational generation typically enumerate in their texts the facts of life and acquisition of material objects. Discussion. The classical and non-classical approaches to the problem of generations are considered as two alternatives of knowledge representation. The conclusion is made regarding the prospects of applying the constructionist approach to the psychology of generations. 


\section{Keywords}

generation, classical approach, non-classical approach, attributes of identification with generation, typological characteristics of generation, type of mentality, innovative mentality, traditional mentality, informational generation, transitional generation

\section{Highlights}

- The classical approach defines the generation as a poorly structured social group.

- The non-classical approach defines the generation as a form of cultural and collective representations.

- The classical approach suggests that the characteristics identifying generations are stable and passed on from generation to generation.

- From the constructionist point of view the characteristics identifying generations are flexible and unstable and are not transmitted across generations directly.

- The typology of generations has its cultural, social, and historical specific qualities.

\section{Acknowledgments}

This study received funding from the Russian Foundation for Basic Research for studying the Dynamics of Values in Generations as a Marker of Transformation of Social Relations in Russian Society, project no. 18-013-00910.

\section{For citation}

Pishchik V.I. Typological and Identifying Characteristics of Generations. Rossiiskii psikhologicheskii zhurnal - Russian Psychological Journal, 2018, V. 15, no. 2, pp. 215-236 (in Russian). DOI: 10.21702/rpj.2018.2.9

Original manuscript received 26.09.2017

\section{Введение}

Актуальность настоящего исследования продиктована тем, что в мире начинает все отчетливее проступать проблема противоречивого, конфликтного взаимодействия людей разных поколений $[1,2,3,4,5,6,7,8,9,10,11]$. Поколенческий концепт [12] более пластичен по отношению к устоявшимся в науке критериям классификации общественных, социальных образований. Однако остается до конца невыясненным вопрос определения системообразующих, социально-психологических характеристик поколений, определяющих их идентификационные и типологические признаки. Заявленная проблема имеет сегодня повышенную актуальность с методологических позиций в связи с тем, что набирает силу конструкционистская методология в вопросах происхождения и устойчивости социальных явлений [13]. Актуальность исследования 
определила цель статьи - изучить идентификационные и типологические признаки поколений с позиции классического (примордиализм) подхода, в котором социальные явления трактуются как неизменные константы, и неклассического (конструкционизм) подхода, в котором социальные явления понимаются процессуально, как изменяемые. Статья является продолжением начатого нами ранее исследования поколений [14].

\section{Дифференцирующие и идентификационные признаки поколений}

Можно акцентировать различные основания определения понятия «поколение»: эволюционное, генеалогическое, демографическое, историкокультурное [15]; антропологическое, историческое, хронологическое, символическое [16]. Преимущественно, авторы описывают либо динамику поколенческих групп в истории с фиксированными «символическими» ценностями каждого из них $[17,18,19]$, либо статическую составляющую поколения, центрируясь на возрасте и генеалогии семей [20, 21, 22].

При этом поколение понимается как условная, длительная социальная группа, организованная стихийно. Отмечается низкая сплоченность в группе поколений. В результате некоторые авторы приходят к выводу, что единение поколения как социальной общности происходит только на этапе первичной социализации и социального обособления поколений в рамках системы образования. Дальнейшая значимость поколенческой общности ослабевает, и пути представителей поколения все более биографизируются [17]. Таким образом, подчеркивается временность, мнимость данного образования. Поколение можно отнести к неструктурированному сообществу. Годы жизни поколения составляют, в среднем, период около 15 лет.

Наиболее часто исследователи представляют три объективных критерия дифференциации поколений: социальную роль в семье [7, 23], историческую эпоху жизни $[2,17]$ и возраст $[6,18]$. Но, как показано J. Macnicol, время жизни не равно возрасту [24]. H. Becker отмечает биографические характеристики поколения (жизненный путь, ценностные ориентации, поведенческие образцы); системные характеристики (размер, состав поколения, поколенческую культуру, поколенческие союзы) [12]. В.М. Воронков в качестве дифференцирующего критерия поколений рассматривает совместную деятельность [2]. W. Strauss, N. Howe определяют важнейшие критерии разделения поколений - среду формирования, архетипы, ценности [11]. Т.П. Емельянова дифференцирующими признаками поколений считает социальные представления, переживания событий общественной жизни [3].

В социальной психологии Г.Г. Дилигенский [25] ставил вопрос о взаимосвязи объективной социальной общности и общности социально-психологической. Мы в большей степени центрируемся на социально-психологических 
характеристиках поколений. Дифференцирующим признаком поколений для нас является тип ментальности [5].

Поколение мы определяем как социальную общность (общность указывает на общее свойство) людей, объединенных схожим типом ментальности, осознающих себя представителями определенного типа поколения по признаку отношения к историческим событиям, протекающим в периоды активности их жизни, связанному с поколением и культурно закрепленному. Это рабочее определение, поскольку в дальнейшем по тексту оно будет несколько меняться.

В любых исторических рамках есть доминирующее поколение, поколение, готовящееся стать доминантным, и поколение, которое не имеет уже столько активности, как доминирующее. В нашем исследовании типология современных поколений рассчитана от эпохи перестройки. Хронологические рамки перестройки - 1985-1991 гг. На наш взгляд, это наиболее весомое, переломное событие в жизни поколений нашей страны. Таким образом, можно обозначить «советское» поколение, «доперестроечное»: годы рождения - около 30 лет до перестройки (1946-1964 гг.). Представители, рожденные с 1965 по 1982 гг. (около 15 лет до перестройки) - это «переходное» поколение. Следующее поколение будет рождено в перестройку. Представители, рожденные, начиная с 1983 г., относятся к «постсоветскому», «информационному» поколению. С 2000 г. (15 лет после начала перестройки) - это «новое», «сетевое», «постперестроечное» поколение.

Дифференцирующие признаки поколения не всегда сочетаются с идентификационными признаками представителей поколений. Мы можем идентифицироваться с определенными доминирующими признаками поколения, но для каждого человека они будут свои. Речь идет о субъективных критериях идентификации с тем или иным поколением. В этом, на наш взгляд, заключена пластичность идентификации с поколением.

Наши исследования $[14,15]$ позволяют заключить, что три субъективных фактора и один объективный могут определить поколение (возраст, переживание исторического события, степень идентификации с поколением и тип ментальности). Но, как показано в наших работах, не всегда эти четыре фактора совпадают. Например, представители «переходного» поколения могут быть близки по возрасту и событийному фактору, но идентифицироваться с «советским поколением», которое им предшествует. Хронологическое время жизни вовлекает в биографию индивидуальные жизненные истории, историческое время (исторический контекст, в котором живут определенные возрастные когорты), создающие опыт поколений. Здесь возникает несовпадение социального и биологического времени. Исходя из этого, возраст не является стабильной характеристикой поколений. Полагаем, что 


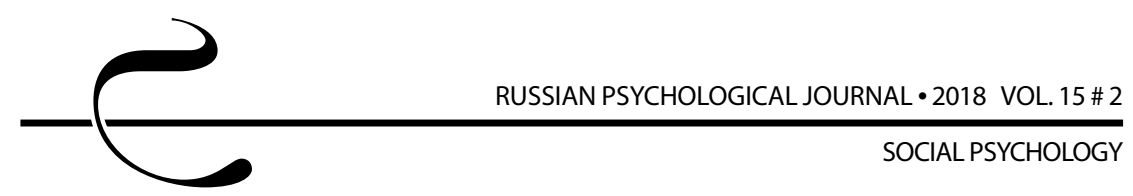

содержательное наполнение идентификационных признаков поколения в различных концепциях будет определять теоретическая позиция автора. Если за основу брать объективный фактор, то можно игнорировать самоидентификацию представителей поколения.

Мы обращаемся к двум подходам в психологии - классическому и неклассическому, основываясь на представлениях В.С. Степина о классическом, неклассическом и постнеклассическом типах рациональности в науке [26], а также на взглядах других авторов, рассматривающих традиционализм и конструктивизм [27].

\section{Классический подход в рассмотрении поколений}

С позиции классического подхода поколение рассматривается как большая социальная, малоструктурированная группа, идентификация представителей которой происходит по историческим, возрастным, событийным, социальнопсихологическим признакам. В рамках «идентитарной, группистской идиомы» [28] группы поколений рассматриваются как субстанциальные, объективно определяемые сущности. Поэтому в классическом подходе субъективные и объективные характеристики поколений максимально приближены. В таком случае мы рассматриваем более узкий контекст исторической активности поколения, его совместную деятельность. С позиции классического подхода, поколение представляет собой социальную группу людей, объединенных общей картиной мира, образом жизни, схожим репертуаром коммуникативных стратегий, общими стилями мышления и общей культурно-исторической ситуацией развития. Т.Д. Марцинковская, Н.С. Полева определяют поколение как «одну из форм неструктурированной большой группы, объединяющей людей с общими социальными представлениями, ценностными ориентациями и отношением к миру» [29, с. 28]. Поколение может объединять людей одного возраста. «Главным» возрастом для идентификации с поколением является подростковый возраст. При этом мы опираемся на представления ряда авторов $[1,7,8,10,11]$, которые акцентируют внимание на исторических событиях, сопровождающих формирование идентичности человека в подростковом возрасте в период с 11 по 16 лет. В этом возрасте у подростков возникает критическое отношение к миру взрослых, формируются ценности. Можно утверждать, что именно в этот период поколенческая идентичность человека определяется ценностно.

Рассмотрим типологию поколений с классических позиций. Из концепции трехуровневой композиции развития больших групп (композиция включает типологический, идентификационный и солидаристский уровни) Г.Г. Дилигенского [25] следует, что типологический уровень предполагает типологию поколений по внешнему признаку. Например, поколения, годы 
жизни которых охватывают эпоху социализма, довоенные и послевоенные, поколения оттепели и т. д. Такие типологии поколений представлены В социологии $[16,17,18]$.

Идентификационный уровень поколений характеризуется наличием у ее представителей самосознания принадлежности к поколению («потерянное поколение», «поколение пепси», «поколение Z»). Солидаристский уровень характеризуется осознанием представителями поколений общности своих интересов, готовности группы к совместным действиям во имя групповых целей. До уровня солидарности поколенческая группа может и не дойти.

Большинство классических типологий поколений исходят из возрастных границ и исторических событий, годов рождения представителей поколений. W. Strauss, N. Howe выделили следующие американские поколения: «потерянное» (1880-1900 гг. р.), «величайшее» (1901-1924 гг. р.), «молчаливое поколение» (1925-1945 гг. р.), «поколение Беби-Бумеров» (1946-1964 гг. р.), «по-

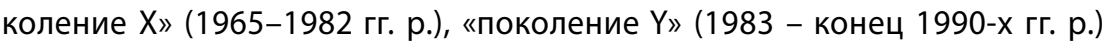
и «поколение Z» (начало 1990-х - 2000-е гг. р.) [11].

В работе Н.C. Yu \& P. Miller акцентируется культурная составляющая типологии поколений [30]. Поколения разделяются на восточные, европейские, азиатские.

C.P. Egri \& D.A. Ralston выявили различные поколения в Китае: «республиканское» (1930-1950 гг. р.), поколение «консолидации» (1951-1960 гг. р.), поколение «культурной революции» (1961-1970 гг. р.), и поколение «социальной реформы» (1971-1975 гг. р.) [19].

А.В. Толстых подразделял российские поколения на: 1) «поколение 1920-х гг. р.»; 2) «поколение 1931-1940 гг. р.»; 3) «первое послевоенное поколение»; 4) «поколение 1950-1960 гг. р.»; 5) «поколение 1970-1980 гг. р.» [9].

В нашей типологии представляем следующие типы: «советское» поколение - носитель традиционной ментальности (1945-1963 гг. р.); «переходное» поколение, «неверящее» - носитель традиционной и переходной ментальностей (1962-1980 гг. р.); «перестроечное», «информационное» поколение с выраженной инновационной ментальностью (1981-1999 гг. р.); «новое», «сетевое» поколение с выраженной постинновационной ментальностью (2000-2018 гг. р.); поколение «глобального прорыва» (предположительно, формирование новой, традиционной ментальности) (2019-2037 гг. р.).

Обобщив исследования поколений с позиции классического подхода, можно определить следующие идентификационные признаки поколений:

- это годы, на которые пришелся подростковый возраст поколения;

- значимые исторические события в годы становления ценностной структуры; 


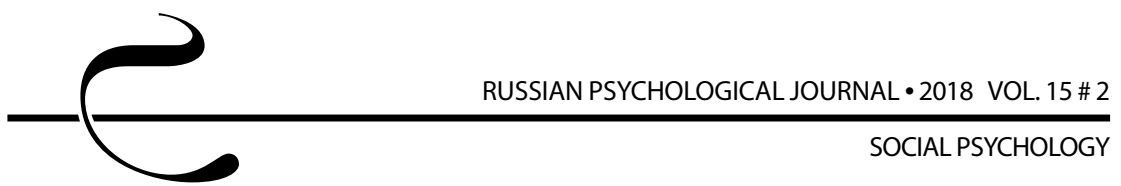

- ведущая деятельность (для ушедшего поколения) - память, напоминание; для старшего поколения - это сохранение традиций и передача опыта; для зрелых - это поддержание и обеспечение молодых; для молодых - это нарушение традиций, инновации;

- когнитивная составляющая - общие, схожие представления, оценки, мнения, знания;

- эмоциональное единство - общие чувства, чувство солидарности в отдельных моментах.

С позиции классического подхода типологические признаки поколения выявляются статистическим большинством, идентификационные признаки связаны с отличительными характеристиками.

\section{Неклассический взгляд на поколения}

С позиции неклассического подхода мир описывается как текучая реальность $[28,31]$. Полагается, что в мире не хватает паттернов, кодексов и правил, которым могли бы подчиняться люди для устойчивости своего положения. Паттерны поведения многочисленны и противоречат друг другу. Человек сам себе определяет образ жизни, поскольку ему не на что полагаться [31]. Господствует представление о том, что идентичность формируется в доминирующих в обществе дискурсах [28], а через них может существовать и влиять на жизнедеятельность поколений. Если в классическом подходе предикторы идентичности жестко заданы, то в неклассическом подходе задаются «мягкие предикторы» идентичности, к которым относят конструируемость, случайность, нестабильность, множественность, текучесть. Идентичность в этом случае является множественной, текучей, постоянно переопределяемой.

Текучесть идентичности представителей поколений затрудняет их определение. М.С. Гусельцева поясняет это как методологическую проблему, отмечая «смещение (лабильность) и смешение (антиномичность) системы ценностей» [32]. В.В. Семенова полагает, что представителей поколения объединяют общее смысловое поле, общее понимание происходящего, сетевая коммуникация [16]. Можно определить следующие положения неклассического подхода к проблеме - поколение объединяется сетью, в ней правят законы не общности, а связности. Связность может определяться непостоянством связей и их недолговременностью и быстрой сменяемостью. Важнейшими характеристиками идентификации представителей поколений выступают социальные отношения, которые складываются внутри и вне поколений. Представляется, что характеристики поколений не являются неизменными, а текучи, изменяемы и специфичны. Видимо, с этих позиций поколение представляет собой мягкую систему, которая очень чувствительна к внешним воздействиям и неустойчива. То есть люди могут принадлежать 
одному поколению, а затем с легкостью идентифицироваться с иным поколением, смотря какой признак будет доминировать в дискурсе общества.

Сегодня можно наблюдать размывание различных видов идентичности поколений [33]. Поскольку поколение имеет свой хронотоп, то важна темпоральная идентичность. В одном из исследований [5] мы показали, что представители «традиционного» поколения больше ориентированы на прошлое, а представители «информационного» ориентированы на будущее. Однако в работе В.А. Емелина, А.Ш. Тхостова [34] высказывается предположение, что прошлое, настоящее и будущее должны находиться в равновесии, иначе это оборачивается деградацией других видов идентичности (маргинальной, виртуальной). С неклассических позиций поколения следует трактовать как коллективные культурные репрезентации, как способы рассмотрения, понимания, анализа социального опыта и интерпретации социального мира. Поколенческие группы существуют только в нашем восприятии. Поколение - не онтологическая реальность, а эпистемологическая реальность. Определяют поколение публичные (воплощенные в текстах, разговоре, памятниках и др.) ментальные репрезентации. Например, «советское» поколение представляет переломный момент истории страны, как «развал» СССР, а «молодое» поколение это же событие в большей степени видит как перестройку. Возможно, формирование этих культурных репрезентаций зависит от вытесняемой тревоги «старшими» поколениями, от непонимания нового мира «младшими» поколениями.

Сделаем предварительные выводы. Можно составить краткий список критериев оценки идентификации и типологии поколений с позиции рассматриваемых подходов: теоретические основания подхода к проблеме; идентификационные признаки поколений; основания типологии поколения; характеристики общности; особенности идентичности; основания единства.

В таблице 1 представлены следующие показатели классического подхода рассмотрения поколений: «поколение - это группа»; «идентификацию поколения определяет совместная активность»; «общность атрибутов группы поколений»; «групповая принадлежность и солидарность», «идентичность характеризуется устойчивостью». Как альтернативные показатели неклассического подхода к поколению определяются следующие: «поколение - это коллективные репрезентации»; «членство в поколении определяют сетевые отношения»; «текучесть идентичности»; «основа единства - комбинированность, разнородность, процессуальность». В неклассическом подходе акцентируется сетевое общество. С неклассических позиций типологические признаки поколения выявляются на короткий период времени, идентификационные признаки связаны с модой. Поколение, таким образом, - это способ понимания мира. 
Таблица 1. Сравнение представлений классического и неклассического полхоАОВ к рассмотрению иАентичности поколений

Table 1. Comparison of classical and non-classical approaches to the identity of generations

\begin{tabular}{|c|c|c|c|}
\hline \multirow[t]{3}{*}{ № } & & \multicolumn{2}{|c|}{$\begin{array}{c}\text { Подходы } \\
\text { Approaches }\end{array}$} \\
\hline & & $\begin{array}{c}\text { К^ассический } \\
\text { Classical }\end{array}$ & $\begin{array}{c}\text { Нек^ассический } \\
\text { Non-classical }\end{array}$ \\
\hline & $\begin{array}{l}\text { Основные } \\
\text { представления } \\
\text { Basic assumptions }\end{array}$ & & \\
\hline 1 & $\begin{array}{l}\text { Теоретические } \\
\text { основания } \\
\text { Theoretical } \\
\text { background }\end{array}$ & $\begin{array}{c}\text { Социальная психоло- } \\
\text { гия больших групп } \\
\text { Social psychology of } \\
\text { large groups }\end{array}$ & $\begin{array}{l}\text { Сетевая теория } \\
\text { Network theory }\end{array}$ \\
\hline 2 & $\begin{array}{l}\text { Илентифокиционные } \\
\text { признаки поколения } \\
\text { Identifying characteris- } \\
\text { tics of generations }\end{array}$ & $\begin{array}{c}\text { Совместная деятель- } \\
\text { ность, цель } \\
\text { Joint activity, objective }\end{array}$ & $\begin{array}{c}\text { Отношения } \\
\text { с Аругими, } \\
\text { сопринадлежность } \\
\text { Relations with Others, } \\
\text { co-affiliation }\end{array}$ \\
\hline 3 & $\begin{array}{l}\text { Основания типологии } \\
\text { поколения } \\
\text { Foundation for the ty- } \\
\text { pology of generations }\end{array}$ & $\begin{array}{l}\text { Категории } \\
\text { Categories }\end{array}$ & $\begin{array}{c}\text { Сети } \\
\text { Networks }\end{array}$ \\
\hline 4 & $\begin{array}{l}\text { Характеристики } \\
\text { общности } \\
\text { Community } \\
\text { characteristics }\end{array}$ & $\begin{array}{l}\text { Общие атрибуты } \\
\text { Common attributes }\end{array}$ & $\begin{array}{c}\text { Социальные } \\
\text { отношения } \\
\text { Social relations }\end{array}$ \\
\hline 5 & $\begin{array}{l}\text { Особенность } \\
\text { иАентичности } \\
\text { Identity characteristic }\end{array}$ & $\begin{array}{c}\text { Устойчивость } \\
\text { Stable }\end{array}$ & $\begin{array}{l}\text { Текучесть } \\
\text { Liquid }\end{array}$ \\
\hline 6 & $\begin{array}{l}\text { Основания еАинства } \\
\text { Foundations for unity }\end{array}$ & $\begin{array}{l}\text { Солидарность } \\
\text { Solidarity }\end{array}$ & $\begin{array}{c}\text { Комбинированность } \\
\text { Combination }\end{array}$ \\
\hline
\end{tabular}




\section{Методы}

В качестве иллюстрации отличительных признаков поколений было проведено исследование в группах двух поколений. В исследовании участвовали представители «переходного» и «информационного» поколений (они идентифицировали себя с данными поколениями), всего 300 человек (студенты старших курсов вузов г. Ростова-на-Дону ( $N=143,86$ мужчин и 57 женщин), возраст 21-23 года; работающие зрелые люди ( $\mathrm{N}=157,82$ мужчины и 75 женщин), возраст 45-50 лет).

Применялась методика измерения ментальности (В.И. Пищик). Она позволяет определить четыре типа ментальности: традиционную, переходную, инновационную и постинновационную. Оцениваются составляющие ментальности: архетипы, стиль мышления, образ мира, образ жизни, отношения, взаимодействие. Определяется, к каким типам ментальности эти составляющие относятся.

Применив метод свободных описаний на тему «Мой подростковый возраст», мы собрали тексты у представителей различных поколений. Инструкция, которая давалась респондентам: «Просим Вас описать в свободной форме воспоминания, которые у Вас связаны с периодом подросткового возраста. Опишите события, сопровождающие этот возраст». Далее провели контент-анализ текстов (2017 г.). Анализ текстов проводился с помощью 16-ти категорий, представленных в таблице 2. Сравнивались профили упоминания категорий. Обосновывали предположение о том, что у поколений различная дискурсивная реальность.

\section{Результаты}

В группе «переходного» поколения были выражены как типы традиционной, так и инновационной ментальности. В зоне традиции находятся только архетипы и особенности отношений к делу, себе и Другим (значимость различий с остальными типами ментальности на уровне $p<0,001)$. Архетипы как базовые основания ментальности играют значимую роль и определяют тип ментальности. Остальные составляющие - образ мира, образ жизни, стиль мышления и особенности взаимодействия - находятся в зоне инновации. Но вместе с тем только образ мира значимо отличается от традиции ( $<<0,001)$. Ментальность в группе «информационного» поколения была инновационного типа. В зоне инновации находятся архетипы (но нет значимых различий с традицией), образ мира, образ жизни и особенности взаимодействия значимо выше традиции (значимость различий с остальными типами ментальности на уровне $\mathrm{p}<0,001)$. В зоне постинновации находятся стиль мышления, особенности отношений, но отличия незначимы.

Как показал анализ текстов, поколения живут в различном дискурсивном пространстве. Оценивался средний балл появления события ( $\max =10)$. 
У переходного поколения они более социоэтальные (М (средние значения) $=6,3 ; \mathrm{SD}=2,0)$, а у информационного поколения - индивидуалистические $(M=7,3 ;$ SD = 2,1). В таблице 2 представлены результаты. Значимость различий указывает на отличие выраженности категории для каждой группы поколений.

Таблица 2. Выраженность категорий в текстах поколений

Table 2. Manifestation of categories in the texts produced by the representatives of generations

\begin{tabular}{|c|c|c|c|}
\hline $\begin{array}{l}\text { Kaтегории } \\
\text { Categories }\end{array}$ & $\begin{array}{c}\text { "ППере- } \\
\text { ходное॥ } \\
\text { покомение } \\
\text { Transitional } \\
\text { generation }\end{array}$ & $\begin{array}{c}\text { "Информа- } \\
\text { ционноел } \\
\text { поколение } \\
\text { Informat- } \\
\text { ional } \\
\text { generation }\end{array}$ & $\begin{array}{c}\text { Значимость } \\
\text { размичий } \\
\text { (Критерий } \\
\text { U Манна - } \\
\text { Уитни) } \\
\text { Significance } \\
\text { of the dif- } \\
\text { ference } \\
\text { (Mann - } \\
\text { Whitney } \\
\text { U-test) }\end{array}$ \\
\hline & \multicolumn{2}{|c|}{$\%$} & \\
\hline $\begin{array}{l}\text { 1. Значимые события (описыва- } \\
\text { ются или одно, или несколько) } \\
\text { Significant events (respondents } \\
\text { describe one or several events) }\end{array}$ & 53 & 61 & 0,070 \\
\hline $\begin{array}{l}\text { 2. Негативные эмоции } \\
\text { Negative emotions }\end{array}$ & 63 & 42 & 0,20 \\
\hline $\begin{array}{l}\text { 3. Позитивные эмоции } \\
\text { Positive emotions }\end{array}$ & 47 & 58 & 0,050 \\
\hline $\begin{array}{l}\text { 4. Участники событий (семья, } \\
\text { Арузья) } \\
\text { Event participants (family, friends) }\end{array}$ & 55 & 60 & 0,045 \\
\hline $\begin{array}{l}\text { 5. Мера ответственности во мне } \\
\text { Measure of self-responsibility }\end{array}$ & 47 & 58 & 0,033 \\
\hline
\end{tabular}




\begin{tabular}{|c|c|c|c|}
\hline $\begin{array}{l}\text { Категории } \\
\text { Categories }\end{array}$ & $\begin{array}{c}\text { "Пере- } \\
\text { ходное" } \\
\text { поколение } \\
\text { Transitional } \\
\text { generation }\end{array}$ & $\begin{array}{c}\text { "Информа- } \\
\text { ционное» } \\
\text { покомение } \\
\text { Informat- } \\
\text { ional } \\
\text { generation }\end{array}$ & $\begin{array}{c}\text { Значимость } \\
\text { размичий } \\
\text { (Критерий } \\
\text { U Манна - } \\
\text { Уитни) } \\
\text { Significance } \\
\text { of the dif- } \\
\text { ference } \\
\text { (Mann - } \\
\text { Whitney } \\
\text { U-test) }\end{array}$ \\
\hline & \multicolumn{2}{|c|}{$\%$} & \\
\hline $\begin{array}{l}\text { 6. Ответственность лежит на } \\
\text { Аругих } \\
\text { Responsibility lies with Others }\end{array}$ & 53 & 42 & 0,061 \\
\hline $\begin{array}{l}\text { 7. ИнАивиАуальное решение } \\
\text { проблемы } \\
\text { Individual problem solving }\end{array}$ & 42 & 81 & 0,023 \\
\hline $\begin{array}{l}\text { 8. Опора на Аругих в решении } \\
\text { проблем } \\
\text { Support of Others in problem } \\
\text { solving }\end{array}$ & 83 & 33 & 0,001 \\
\hline $\begin{array}{l}\text { 9. Наличие цели } \\
\text { Existence of an objective }\end{array}$ & 90 & 80 & 0,067 \\
\hline $\begin{array}{l}\text { 10. Отсутствие цели } \\
\text { Absence of an objective }\end{array}$ & 10 & 20 & 0,077 \\
\hline $\begin{array}{l}\text { 11. ГорАость за Аостижения } \\
\text { Pride in achievements }\end{array}$ & 60 & 92 & 0,000 \\
\hline
\end{tabular}




\begin{tabular}{|c|c|c|c|}
\hline $\begin{array}{l}\text { Категории } \\
\text { Categories }\end{array}$ & $\begin{array}{c}\text { "ППере- } \\
\text { ходное॥ } \\
\text { поколение } \\
\text { Transitional } \\
\text { generation }\end{array}$ & $\begin{array}{l}\text { "Иноорма- } \\
\text { ционное॥ } \\
\text { поколение } \\
\text { Informat- } \\
\text { ional } \\
\text { generation }\end{array}$ & $\begin{array}{c}\text { Значимость } \\
\text { различий } \\
\text { (Критерий } \\
\text { U Манна - } \\
\text { Уитни) } \\
\text { Significance } \\
\text { of the dif- } \\
\text { ference } \\
\text { (Mann - } \\
\text { Whitney } \\
\text { U-test) }\end{array}$ \\
\hline & \multicolumn{2}{|c|}{$\%$} & \\
\hline $\begin{array}{l}\text { 12. Разделяемые Аостижения } \\
\text { с Аругими } \\
\text { Sharing achievements with } \\
\text { Others }\end{array}$ & 79 & 40 & 0,016 \\
\hline $\begin{array}{l}\text { 13. Описаны социальные роли } \\
\text { Respondents describe social } \\
\text { roles }\end{array}$ & 73 & 45 & 0,028 \\
\hline $\begin{array}{l}\text { 14. Описаны личностные } \\
\text { особенности } \\
\text { Respondents describe personal } \\
\text { characteristics }\end{array}$ & 20 & 69 & 0,061 \\
\hline $\begin{array}{l}\text { 15. Описана совместная } \\
\text { Аеятельность } \\
\text { Respondents describe joint } \\
\text { activities }\end{array}$ & 85 & 44 & 0,001 \\
\hline $\begin{array}{l}\text { 16. Описана инАивидуальная } \\
\text { деятельность } \\
\text { Respondents describe individual } \\
\text { activities }\end{array}$ & 37 & 80 & 0,000 \\
\hline
\end{tabular}


В группе «переходного» поколения среди значимых событий были обозначены: полет человека в космос, Афганская война, перестройка, олимпиада в Москве, взрыв на Чернобыльской АЭС, экономический кризис, война в Сирии, в Украине. Негативные эмоции были связаны с утратами, ущемлением интересов страны. Позитивные эмоции связаны с достижениями страны. Мера ответственности была разделена равномерно между собой и Другими. Опора на Других в решении проблем была более выражена в текстах. Деятельность была описана как целенаправленная. Представители описали больше совместную деятельность. Выделены качества, присущие поколению: адекватная самооценка, осторожность, трудолюбие, откровенность, вдумчивость, справедливость.

В группе «информационного» поколения значимыми событиями истории страны были обозначены следующие: олимпиада в Сочи, война в Украине, новые компьютерные технологии, присоединение Крыма, введение санкций против России. Негативные эмоции были связаны с ущемлением личных интересов и политических интересов страны. Позитивные эмоции связаны с личными достижениями. Мера ответственности была отнесена в большей степени к Другим, чем к себе. Индивидуальное решение проблемы было более выражено в текстах. Представители описали больше индивидуальную деятельность. Отмечены качества представителей поколения: энергичность, пассивность, активная позиция, материальная ориентация.

Тексты представителей поколения «переходных» содержат больше информации о культурной насыщенности жизни, акцентируют дискомфорт и вынужденность, разрушение некоторых социальных норм. Тексты «информационного» поколения изобилуют данными об информационных новинках и доступе к ним, своих достижениях, приобретениях.

\section{Обсуждение результатов}

С позиции классического подхода поколение - это стабильная группа, заключенная в рамки исторического события и времени жизни, которые определяют его жесткие типологические и идентификационные признаки. С позиции неклассического подхода поколение - текучее, непостоянное образование, наполняемое различным содержанием, как с типологических, так и идентификационных признаков, определяемых различным общественным дискурсом. Изложенные два подхода к проблеме поколений могут сосуществовать как два альтернативных направления развития системы знания о поколении в связи с новой позицией в понимании научной преемственности знания, как более расширенной, как сложной самоорганизующейся системы [26].

Эмпирическое исследование показало, что у представителей «информационного» поколения выражены преимущественно традиционная 


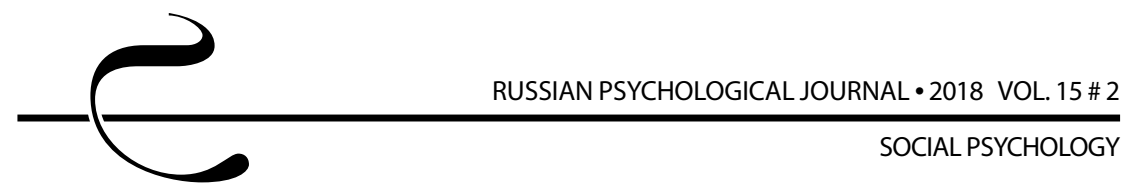

и инновационная ментальности; у представителей «переходного» поколения выражена преимущественно инновационная ментальность. Это может свидетельствовать о том, что в обществе востребованы индивидуалистические ценности, активность, приоритет личных интересов. Анализируемые тексты рассматриваемых поколений отразили их различия в отношении выделяемых значимых исторических событий, ответственности, целеполагания, включенности Других в их жизненные сферы.

Данное исследование предполагает дальнейшее проведение более масштабных измерений дискурсов представителей различных типов поколений.

Понимание различий поколений и «разрыва» между ними имеет множество применений во всех областях жизни: в консультировании детско-родительских отношений, педагогическом пространстве, отношениях поколений в организациях и в продажах.

\section{Литература}

1. Рикель А. М., Доренская С. В. Социально-психологическая модель ценностей различных поколений современного российского общества // Российский психологический журнал. 2017. T. 14, № 4. С. 205-225. DOI: 10.21702/rpj.2017.4.10

2. Воронков В. М. Проект «шестидесятников»: движение протеста в СССР // Отцы и дети. Поколенческий анализ современной России / сост. Ю. Левада, Т. Шанин. М.: Новое литературное обозрение, 2005. С. 168-200.

3. Емельянова Т. П. Социальные представления. История, теория и эмпирические исследования. М.: Когито-Центр, 2016. 476 с.

4. Кон И. С. Ребенок и общество. М.: Академия, 2003. 336 с.

5. Пищик В. И. Поколения: социально-психологический анализ ментальности // Социальная психология и общество. 2011. № 2. С. 80-88.

6. Постникова М. И. Психология отношений между поколениями в современной России: дисс. ... д. психол. наук. СПб., 2010. 590 с.

7. Сапоровская М. В. Психология межпоколенных отношений в современной российской семье. Кострома: Изд-во КГУ им. Н. А. Некрасова, 2012. 430 c. URL: http://www.coping-kostroma.com/images/files/SaporovskayaBook.pdf (дата обращения 12.05.2018).

8. Sánchez-Moya A., Cruz-Moya O. Whatsapp, Textese, and Moral Panics: Discourse Features and Habits Across Two Generations // Procedia - Social and Behavioral Sciences. 2015. Vol. 173. P. 300-306. DOI: 10.1016/j.sbspro.2015.02.069

9. Толстых А. В. Опыт конкретно-исторической психологии личности. СПб.: Алтея, 2000. 287 с. 
10. Kupperschmidt B. R. Multigeneration Employees: Strategies for Effective Management // The Health Care Manager. 2000. Vol. 19, Issue 1. P. 65-76. DOI: 10.1097/00126450-200019010-00011

11. Howe N., Strauss W. Millennials Rising:The next great generation. New York: Vintage, 2009. $432 \mathrm{p}$.

12. Campbell S. M., Twenge J. M., Campbell W. K. Fuzzy But Useful Constructs: Making Sense of the Differences Between Generations // Work, Aging and Retirement. 2017. Vol. 3, Issue 2. P. 130-139. DOI: 10.1093/workar/wax001

13. Джерджен К. Социальный конструкционизм: знание и практика: Сб. статей / пер. с англ. А. М. Корбута; под общ. ред. А. А. Полонникова. Мн.: Изд-во БГУ, 2003. 232 с.

14. Пищик В. И., Сиврикова Н. В. Динамика смысловых составляющих ментальности поколений // Российский психологический журнал. 2014. Т. 11, № 3. С. 73-82.

15. Пищик В. И., Гаврилова А. В., Сиврикова Н. В. Стили межпоколенного педагогического взаимодействия преподавателей и студентов разных поколенческих групп // Российский психологический журнал. 2016. T. 13, № 3. C. 245-264. DOI: $10.21702 /$ rpj.2016.3.14

16. Семенова В. В. Социальная динамика поколений: проблема и реальность. М.: Российская политическая энциклопедия (РОССПЭН), 2009. 271 с.

17. Левада Ю. А. Поколения XX века: возможности исследования // Отцы и дети: поколенческий анализ современной России. М.: Новое литературное обозрение, 2005. С. 39-60.

18. Лисовский В. Т. Динамика социальных изменений (опыт сравнительных социологических исследований российской молодежи) // Социологические исследования. 1998. № 5. С. 98-104.

19. Egri C. P., Ralston D. A. Generation Cohorts and Personal Values: A Comparison of China and the United States // Organization Science. 2004. Vol. 15, Issue 2. P. 210-220. DOI: $10.1287 /$ orsc.1030.0048

20. Мангейм К. Очерки социологии знания: Проблема поколений - Состязательность - Экономические амбиции. М.: Изд-во ИНИОН РАН. 2000. 162 c.

21. Солдатова Г. У., Рассказова Е. И. «Цифровая» ситуация развития межпоколенческих отношений: разрыв и взаимодействие между подростками и родителями в Интернете // Мир психологии. 2017. № 1 (89). С. 134-143.

22. Глотов М. Б. Поколение как категория социологии // СоцИс. 2004. № 10. C. 42-49.

23. Мид М. Культура и мир детства. М.: Наука, 1988. 429 с.

24. Macnicol J. Neoliberalising Old Age. Cambridge: Cambridge University Press, 2015. $242 \mathrm{p}$. 


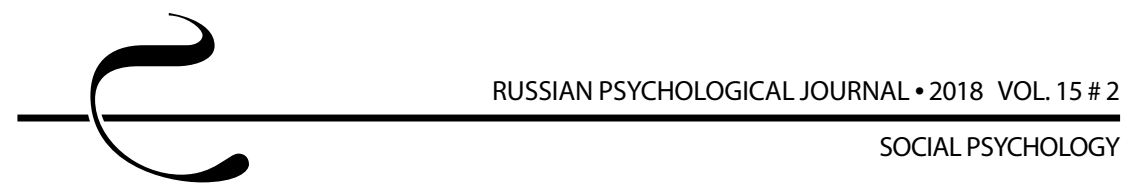

25. Дилигенский Г.Г. Некоторые методологические проблемы исследования психологии больших групп // Методологические проблемы социальной психологии / отв. ред. Е. В. Шорохова. М.: Наука, 1975. С. 196-205.

26. Степин В. С. Теоретическое знание. М.: Прогресс-Традиция, 2000. 744 с.

27. Кроник А. А. Выбор конструктивиста // История российской психологии в лицах: Дайджест. 2016. № 6. С. 500-504.

28. Брубейкер Р. Этничность без групп / пер. с англ. И. Борисовой; Нац. исслед. ун-т «Высшая школа экономики». М.: Изд. дом Высшей школы экономики, 2012. 408 с.

29. Марцинковская Т.Д., Полева Н. С. Поколения эпохи транзитивности: ценности, идентичность, общение // Мир психологии. 2017. № 1 (89). С. 24 -37.

30. Yu H. C. \& Miller P. Leadership style - The X Generation and Baby Boomers compared in different cultural contexts // Leadership \& Organization Development Journal. 2005. Vol. 26, Issue 1. P. 35-50. DOI: 10.1108/01437730510575570

31. Бауман 3. Текучая современность. СПб.: Питер, 2008. 240 с.

32. Гусельчева М. С. Идентичность в транзитивном обществе: трансформация ценностей // Психологические исследования. 2017. Т. 10, № 54. С. 5. URL: http://psystudy.ru (дата обращения: 20.04.2018).

33. Иванова Н. Л., Румянцева Т. В. Социальная идентичность: теория и практика. М.: Изд-во СГУ, 2009. 453 с.

34. Емелин В. А., Тхостов А. Ш. Соблазны и ловушки темпоральной идентичности // Вопросы философии. 2016. № 8. С. 115-125.

35. Стёпин В. С. Историко-научные реконструкции: плюрализм и кумулятивная преемственность в развитии научного знания // Вопросы философии. 2016. № 6. С. 5-14.

\section{References}

1. Rikel' A. M., Dorenskaya S. V. A socio-psychological model of values among different generations in modern Russian society. Rossiiskii psikhologicheskii zhurnal - Russian Psychological Journal, 2017, V. 14, no. 4, pp. 205-225 (in Russian). DOI: 10.21702/rpj.2017.4.10

2. Voronkov V. M. The 'men of the sixties' project: The protest movement in the USSR. In: Levada Yu., Shanin T. (eds.) Fathers and children: A generational analysis of modern Russia. Moscow, Novoe literaturnoe obozrenie Publ., 2005, pp. 168-200.

3. Emel'yanova T. P. Sotsial'nye predstavleniya. Istoriya, teoriya i empiricheskie issledovaniya [Social representations: History, theory, and empirical research]. Moscow, Kogito-Center Publ., 2016. 476 p.

4. Kon I. S. Rebenok i obshchestvo [The child and society]. Moscow, Akademiya Publ., 2003. 336 p. 
5. Pishchik V. I. Generations: Socio-psychological analysis of mentality. Sotsial'naya psikhologiya iobshchestvo-Social Psychology and Society, 2011, no. 2, pp. 80-88 (in Russian).

6. Postnikova M. I. Psikhologiya otnoshenii mezhdu pokoleniyami v sovremennoi Rossii [Psychology of intergenerational relations in modern Russia]. Diss. Dr. Sci. (Psych.). St. Petersburg, 2010. 590 p.

7. Saporovskaya M. V. Psikhologiya mezhpokolennykh otnoshenii v sovremennoi rossiiskoi sem'e [Psychology of intergenerational relations in modern Russian families]. Kostroma, KSU Publ., 2012.430 p. Available at: http://www.copingkostroma.com/images/files/Saporovskaya-Book.pdf (Accessed 12 May 2018).

8. Sánchez-Moya A., Cruz-Moya O. Whatsapp, textese, and moral panics: Discourse features and habits across two generations. Procedia - Social and Behavioral Sciences, 2015, V. 173, pp. 300-306. DOI: 10.1016/j.sbspro.2015.02.069

9. Tolstykh A. V. Opyt konkretno-istoricheskoi psikhologii lichnosti [The experience of concrete historical personality psychology]. St. Petersburg, Alteya Publ., 2000. 287 p.

10. Kupperschmidt B. R. Multigeneration employees: Strategies for effective management. The Health Care Manager, 2000, V. 19, Issue 1, pp. 65-76. DOI: 10.1097/00126450-200019010-00011

11. Howe N., Strauss W. Millennials rising: The next great generation. New York, Vintage, 2009. 432 p.

12. Campbell S. M., Twenge J. M., Campbell W. K. Fuzzy but useful constructs: Making sense of the differences between generations. Work, Aging and Retirement, 2017, V. 3, Issue 2, pp. 130-139. DOI: 10.1093/workar/wax001

13. Gergen K., Polonnikov A. A. (ed.) Sotsial'nyi konstruktsionizm: znanie i praktika [Social constructionism: knowledge and practice]. Minsk, BSU Publ., 2003. $232 \mathrm{p}$.

14. Pishchik V. I., Sivrikova N. V. The dynamics of sense components of the mentality of generations. Rossiiskii psikhologicheskii zhurnal - Russian Psychological Journal, 2014, V. 11, no. 3, pp. 73-82 (in Russian).

15. Pishchik V. I., Gavrilova A. V., Sivrikova N. V. Styles of intergenerational pedagogical interaction between teachers and students of different generational groups. Rossiiskii psikhologicheskii zhurnal - Russian Psychological Journal, 2016, V. 13, no. 3, pp. 245-264 (in Russian). DOI: 10.21702/rpj.2016.3.14

16. Semenova V. V. Sotsial'naya dinamika pokolenii: problema i real'nost' [Social dynamics of generations: The problem and reality]. Moscow, Rossiiskaya politicheskaya entsiklopediya Publ., 2009. 271 p.

17. Levada Yu. A. Generations of the 20th century: Potential for research. In: Levada Yu., Shanin T. (eds.) Fathers and children: A generational analysis of modern Russia. Moscow, Novoe literaturnoe obozrenie Publ., 2005, pp. 39-60. 
18. Lisovskii V.T.The dynamics of social changes: The experience of comparative sociological research of Russian youth. Sotsiologicheskie issledovaniya - Sociological Studies, 1998, no. 5, pp. 98-104 (in Russian).

19. Egri C. P., Ralston D. A. Generation cohorts and personal values: A comparison of China and the United States. Organization Science, 2004, V. 15, Issue 2, pp. 210-220. DOI: 10.1287 /orsc. 1030.0048

20. Mannheim K. Essays on the sociology of knowledge: The problem of generations - competitiveness - economic ambitions (Russ. ed.: Mangeim K. Ocherki sotsiologii znaniya: Problema pokolenii - Sostyazatel'nost' - Ekonomicheskie ambitsii. Moscow, INION RAS Publ., 2000. 162 p.).

21. Soldatova G. U., Rasskazova E. I. The 'digital' situation of intergenerational relations:The gap and interaction between adolescents and parents on the Internet. Mir psikhologii - World of Psychology, 2017, no. 1 (89), pp. 134-143 (in Russian).

22. Glotov M. B. Generation as a category in sociology. Sotsiologicheskie issledovaniya - Sociological Studies, 2004, no. 10, pp. 42-49 (in Russian).

23. Mead M. Kul'tura i mir detstva [Culture and the world of childhood]. Moscow, Nauka Publ., 1988. 429 p.

24. Macnicol J. Neoliberalising old age. Cambridge, Cambridge University Press, 2015. 242 p.

25. Diligenskii G. G. Certain methodological problems of research in the psychology of large groups. In: Shorokhova E. V. (ed.) Metodologicheskie problemy sotsial'noi psikhologii [Methodological problems of social psychology]. Moscow, Nauka Publ., 1975, pp. 196-205.

26. Stepin V. S. Teoreticheskoe znanie [Theoretical knowledge]. Moscow, ProgressTraditsiya Publ., 2000. 744 p.

27. Kronik A. A. The choice of a constructivist. Istoriya rossiiskoi psikhologii v litsakh: Daidzhest - The History of Russian Psychology in Persons: Digest, 2016, no. 6, pp. 500-504 (in Russian).

28. Brubaker R. Ethnicity without groups. Cambridge, Mass., 2004 (Russ. ed. Brubeiker R. Etnichnost' bez grupp. Moscow, Higher School of Economics Publ., 2012. 408 p.).

29. Martsinkovskaya T. D., Poleva N. S. Generations of the transitivity era:Values, identity, and communication. Mir psikhologii - World of Psychology, 2017, no. 1 (89), pp. 24-37 (in Russian).

30. Yu H. C. \& Miller P. Leadership style-The X generation and baby boomers compared in different cultural contexts. Leadership \& Organization Development Journal, 2005, V. 26, Issue 1, pp. 35-50. DOI: 10.1108/01437730510575570

31. Bauman Z. Tekuchaya sovremennost' [Liquid modernity]. St. Petersburg, Piter Publ., 2008. 240 p. 
32. Gusel'tseva M. S. Identity in the transitive society: Transforming values. Psikhologicheskie Issledovaniya - Psychological Studies, 2017, V. 10, no. 54, p. 5 (in Russian). Available at: http://psystudy.ru (Accessed 20 April 2018).

33. Ivanova N. L., Rumyantseva T. V. Sotsial'naya identichnost': teoriya i praktika [Social identity: Theory and practice]. Moscow, MSGI Publ., 2009. 453 p.

34. Emelin V. A., Tkhostov A. Sh. Temptation and traps of temporal identity. Voprosy filosofii - Problems of Philosophy, 2016, no. 8, pp. 115-125 (in Russian).

35. Stepin V. S. Historical and scientific reconstruction: Pluralism and cumulative continuity in the development of scientific knowledge. Voprosy filosofii Problems of Philosophy, 2016, no. 6, pp. 5-14 (in Russian). 